\title{
Review Article \\ Nicotinic Acetylcholine Receptor Signaling in Tumor Growth and Metastasis
}

\author{
Sandeep Singh, Smitha Pillai, and Srikumar Chellappan \\ Department of Tumor Biology, H. Lee Moffitt Cancer Center and Research Institute, 12902 Magnolia Drive, Tampa, FL 33612, USA \\ Correspondence should be addressed to Srikumar Chellappan, srikumar.chellappan@moffitt.org \\ Received 19 December 2010; Accepted 28 January 2011 \\ Academic Editor: Venkateshwar Keshamouni \\ Copyright () 2011 Sandeep Singh et al. This is an open access article distributed under the Creative Commons Attribution License, \\ which permits unrestricted use, distribution, and reproduction in any medium, provided the original work is properly cited.
}

Cigarette smoking is highly correlated with the onset of a variety of human cancers, and continued smoking is known to abrogate the beneficial effects of cancer therapy. While tobacco smoke contains hundreds of molecules that are known carcinogens, nicotine, the main addictive component of tobacco smoke, is not carcinogenic. At the same time, nicotine has been shown to promote cell proliferation, angiogenesis, and epithelial-mesenchymal transition, leading to enhanced tumor growth and metastasis. These effects of nicotine are mediated through the nicotinic acetylcholine receptors that are expressed on a variety of neuronal and nonneuronal cells. Specific signal transduction cascades that emanate from different nAChR subunits or subunit combinations facilitate the proliferative and prosurvival functions of nicotine. Nicotinic acetylcholine receptors appear to stimulate many downstream signaling cascades induced by growth factors and mitogens. It has been suggested that antagonists of $\mathrm{nAChR}$ signaling might have antitumor effects and might open new avenues for combating tobacco-related cancer. This paper examines the historical data connecting nicotine tumor progression and the recent efforts to target the nicotinic acetylcholine receptors to combat cancer.

\section{Introduction}

Smoking is a major risk factor associated with the development and progression of a variety of cancers [1]. Smoking is estimated to account for approximately 4-5 million deaths worldwide and approximately 443,000 deaths each year in the United States alone $[2,3]$. Sufficient evidence has accumulated to conclude that tobacco smoking caused cancers not only of the lung, but also of the lower urinary tract including the renal pelvis and bladder, upper aero-digestive tract including oral cavity, pharynx, larynx, and esophagus, and pancreas $[2,4]$. Recent lines of evidence have showed that smoking tobacco can also cause cancers of the nasal cavity, paranasal sinus, nasopharynx, stomach, liver, kidney, cervix, uterus, breast, adenocarcinoma of the esophagus, and myeloid leukemia [2]. Of the thousands of chemicals in tobacco smoke, polycyclic aromatic hydrocarbons and nicotine-derived nitrosamines have been identified as the major and potent carcinogens $[5,6]$. The metabolites of these agents form DNA adducts and cause mutations in vital genes like $\mathrm{Rb}$, p53, and K-Ras in smokers [7-9].

While the induction of these cancers is mediated by tobacco-specific nitrosamines as well as other carcinogens present in the tobacco smoke, it is becoming clear that signaling through the nicotinic acetylcholine receptors contribute to the growth, progression, and metastasis of a variety of cancers. Nicotine, which is the major addictive component of tobacco smoke, acts through nicotinic acetylcholine receptors (nAChR) [9-11], but is not thought to be carcinogenic. The expression of nAChRs in central and peripheral nervous system is associated with smoking dependence and addiction [12]. It was generally believed that nAChRs are only expressed in nervous system and at neuromuscular junctions (muscle type nAChRs). However, the discovery of widespread expression of nAChRs in mammalian cells, including cancers, suggested its direct role in cancer progression [13-15]. This paper deals with certain aspects of nicotinic receptor signaling in nonneuronal 
cells that lead to increased cell proliferation and survival, angiogenesis, tumor growth, and metastasis.

\section{Nicotinic Acetylcholine Receptor Expression in Nonneuronal Cells}

nAChRs are a complex of five subunits forming hetero- or homopentamers to form a central ion channel $[16,17]$. The neuronal nAChRs can be homomeric composed of $\alpha 7, \alpha 8$, or $\alpha 9$ subunits or with the combinations of $\alpha 2-\alpha 6$ or $\alpha 10$ subunits with $\beta 2-\beta 4$ subunits (heteromeric $\mathrm{nAChRs).} \mathrm{The}$ muscle type nAChRs may be comprised of combinations of $\alpha 1$ subunits with $\beta 1, \gamma, \delta$, or $\varepsilon$ subunits [18]. Both neuronal as well as muscle nAChR families are found to be expressed in cancer cells [19]. Nicotine mimics acetylcholine by binding as an agonist to $\alpha$ subunit of nAChRs [10]. Nicotine binds with higher affinity to heteromeric $\alpha 4 \beta 2$-nAChRs than to $\alpha 7$-nAChRs [20]. Higher binding to $\alpha 4 \beta 2$-nAChRs results in desensitization of the receptor, which could be the reason that $\alpha 7-\mathrm{nAChR}$ is the major stimulator of cancer development and progression in vivo. In addition to nicotine, tobacco-specific nitrosamines such as 4-(methylnitrosamino)-1-(3-pyridyl)-1-butanone (NNK) can also bind to $\alpha 7$-nAchR, and $N$-nitrosonornicotine (NNN) binds to heteromeric $\alpha \beta$-nAChRs [21]. The affinity of NNK for the $\alpha 7$-nAChR was found to be 1,300 times higher than nicotine, whereas the affinity of NNN for heteromeric $\alpha \beta$-nAChRs was 5,000 times higher than that of nicotine $[21,22]$.

Since the discovery of ubiquitous presence of nAChRs in mammalian cells, studies from many laboratories have linked nAChRs with various pathological conditions including tumor growth and angiogenesis [13, 23]. In earlier studies, nicotine was found to stimulate endothelial-cell proliferation via $\mathrm{nAChR}$ at concentrations lower than those obtained in blood after smoking [24]. As described in the later part of this paper, many studies have correlated the exposure of nicotine or other tobacco smoke components with induction of pathological neovascularization through the activation of nAChR $[23,25]$. Studies from our laboratory have suggested that nicotine can enhance the growth and metastasis of pre-established lung tumors [26]. Altogether, these studies proposed the involvement of tobacco smoke components in various aspects of tumorigenesis and vascular dysfunctions in smokers. Extensive research by many groups has successfully associated the physiological effect of nicotine and its derivatives with the direct activation of nAChRs. Small cell lung carcinoma (SCLC) pulmonary neuroendocrine cells (PNECs) and SCLC cells express high levels of the $\alpha 7$-nAChR, whereas heteromeric nAChRs were undetectable $[27,28]$. At the same time, both hetero- and homomeric nAChRs are found to be expressed in nonsmall cell lung carcinoma cells of different histologic subtypes $[19,29]$. Recently, differential expression pattern of $A C H R$ subunit gene was studied in NSCLC patients who were smokers or never smokers. Higher expression of CHRNA6 and CHRNB3 combination was correlated with NSCLCs in nonsmokers, whereas lower expression was correlated with NSCLCs in smokers. Additionally, increased expression of CHRNA1, CHRNA5, and CHRNA7 subunit genes was correlated with short-term exposure to nicotine [30]. Nicotine stimulation contributed towards the growth of human mesothelioma cells. Human biopsies of mesothelioma as well as of normal pleural mesothelial cells were found to express functional $\alpha 7$-nAChR $[31,32]$. Studies from the Russo laboratory have shown that inhibition of nAChRs by $\alpha$-cobratoxin $(\alpha$-CBT) can inhibit the growth of A549 tumors in immunocompromised mice [33]. These findings strengthen the hypothesis that modulation of nAChRs upon chronic exposure to tobacco may contribute to the development and progression of cancer. In the following sections, we will summarize the findings to support the hypothesis.

\section{3. nAChRs Signaling in Tumor Growth and Survival}

Attempts have been made to elucidate the molecular events that mediate nicotine-induced cell proliferation. Activation of nAChR through nicotine or NNK has been found to activate protein kinase $\mathrm{C}$ ( $\mathrm{PKC})$, the serine/threonine kinase Raf-1, the mitogen-activated kinases ERK1 and ERK2, and the transcription factors FOS, JUN, and MYC through the selective activation of $\alpha 7-\mathrm{nAChR}$ in SCLC [34]. Studies also demonstrated the stereospecificity of nAChRs towards $(-)$-nicotine. It has been reported that (-)-nicotine stimulated tumor cell proliferation via secretion of the neurotransmitter serotonin, and the growth stimulatory effect of nicotine or NNK could be blocked by selective serotonergic receptor antagonists [27, 35, 36]. In a recent report, the effects of acute and repetitive exposure to nicotine was shown to induce a neuronallike appearance in N417 SCLC cell line, which produced bigger and more vascularized tumors in mice through activation of CXCR4/CXCL12 axis. A prominent increase in the expression of CXCR4 was observed in nAChR-dependent manner in nicotine-treated cells [37]. NSCLC cell lines from large-cell carcinoma, squamous-cell carcinoma, and adenocarcinoma, all showed the activation of PI3K-AKT pathway and NF- $\kappa \mathrm{B}$ activation in response to nicotine or NNK treatment $[38,39]$. In addition, frequent loss of the tumor suppressor gene FOXO3a was reported in carcinogeninduced lung adenocarcinoma. In NNK-treated lung cancer cells, restoration of FOXO3a in FOXO3a-deficient cells increases sensitivity to apoptosis caused by a DNA-damaging intermediate of NNK. This study proposed that FOXO3a might play a role in lung adenocarcinoma suppression by providing a protective response to carcinogenic stress [40].

Experiments from our laboratory have shown that nicotine stimulation affects various components of cell cycle regulatory machinery $[26,29,41]$. Exposure to nicotine resulted in activation of Raf- 1 , induction of cyclin $\mathrm{D}$ and cyclin E-associated kinase activity as well as $\mathrm{Rb}$ phosphorylation, which led to the dissociation of E2F1 from Rb. Further, it was observed that stimulation with nicotine caused the dissociation of Rb from E2F-responsive proliferative promoters ( $c d c 6$ and $c d c 25 A$ ), while there were 
increased amounts of E2F1 bound to them. These molecular events were correlated with increased proliferative effects of nicotine in NSCLC cell lines A549 (human bronchioalveolar carcinoma), NCI-H23, NCI-H441 (lung adenocarcinoma), and NCI-H226 (pleural effusion squamous cell carcinoma) as well as on primary normal human bronchial epithelial cells (NHBEs), small airway epithelial cells (SAECs), human aortic endothelial cells (HAECs), and human microvascular endothelial cells from lung (HMEC-Ls). The mitogenic effects of nicotine were abrogated by $\alpha 7$ subunit antagonists, $\alpha$-bungarotoxin, and methylallyl aconitine (MAA), whereas it was unaffected by $\alpha$-lobeline ( $\alpha 4 \beta 2$ subunit inhibitor) or dihydro $\beta$-erythoidine $(\mathrm{DH} \beta \mathrm{E} ; \alpha 3 \beta 2$ and $\alpha 4 \beta 2$ subunit inhibitor), suggesting that $\alpha 7$ subunits primarily mediated the mitogenic effects of nicotine in NSCLC cells. We have further illustrated that upon nicotine stimulation, the scaffolding protein $\beta$-arrestin-1 forms a complex with nonreceptor tyrosine kinase-Src and gets recruited to the nAChRs. Depletion of $\beta$-arrestin- 1 or Src prevented nicotine-induced cell proliferation. These results suggested that $\alpha 7$-nAChRmediated stimulation of cell proliferation is through a $\beta$-Arrestin-1-Src signaling axis in NSCLC [41]; (see also Figure 1).

Other than lung cancer, activation of $\alpha 7-\mathrm{nAChR}$ and heteromeric nAChRs expressing $\alpha 3$ and $\alpha 5$ subunits have been reported in oral and esophageal keratinocytes [22]. Similar to lung cancer cells, NNK was found to bind with high affinity to $\alpha 7$-nAChR, whereas NNN was found to bind to heteromeric nAChRs with higher affinity [22]. Esophageal cancer-Het-1A cells stimulated with NNK or NNN showed increased mRNA transcripts and expression of PCNA and $\mathrm{Bcl}-2$, and transcription factors GATA3, NF- $\kappa \mathrm{B}$, and STAT1. However, induction of Ras-Raf-ERK1-ERK2 cascade, the JAK2-STAT3 pathway and NF- $\kappa$ B activation was associated with enhanced cell proliferation through these nitrosamines in immortalized oral epithelial cells [22]. In addition, chronic exposure of nicotine or environmental tobacco smoke on oral keratinocytes selectively upregulated $\alpha 5$ - and $\alpha 7$-nAChR subunits, resulting in intensified signaling responses to nicotine [42].

The secreted mammalian Ly-6/urokinase plasminogen activator receptor-related protein-1 (SLURP-1) is recently identified as an endogenous ligand for the $\alpha 7$ subunit of the nicotinic acetylcholine receptor (nAChR). The expression levels of SLURP1 and SLURP2 (secreted mammalian Ly-6/urokinase plasminogen activator receptor-related protein-2) were reduced in NNK-treated cells. Transfection of the cells with SLURP1 or SLURP2 cDNA reduced the nitrosamine-induced colony formation in soft agar while inhibiting the growth of NNK-transformed keratinocytes in mouse xenografts. SLURP1 bound to $\alpha 7$-nAChR and SLURP2 bound to nAChRs expressing the $\alpha 3$ subunit [22, 43]. Similar results were demonstrated recently where HT29 human colon cancer cells treated with nicotine resulted in increased cell proliferation and a marked reduction in the protein expression of SLURP1 via $\alpha 7$-nAChRs activation [44]. Recently, nicotine mediated upregulation of FOXM1 expression was found in primary oral keratinocytes which was associated with induction of genomic instability.
A centrosomal protein CEP55 as well as a DNA helicase and putative stem cell marker HELLS, were found to be novel targets of nicotine-induced FOXM1 expression and correlated with oral cancer progression [45].

A role of nAChR has been demonstrated in breast cancer progression as well. Experiments with human mammary epithelial-like MCF10A or cancerous MCF7 cells revealed that treatment of these cells with nicotine enhances the activity of protein kinase C (PKC) alpha with cdc42 as a downstream target for nicotine-induced proliferation and migration [46]. It has also been suggested that nicotineinduced proliferation of human breast cancer cell is dependent on $\alpha 9$-nAChR and cyclin D3 expression [47]. The effects of nicotine on a population of cancer stem cells in MCF-7 human breast cancer cells were examined, using aldehyde dehydrogenase (ALDH) as a stem cell marker. This study found that nicotine increases the stem cell population via $\alpha 7$-nAChR and the PKC-Notch dependent pathway [48].

Apart from direct responses through nAChRs, indirect signaling events may also contribute to nicotine-induced tumor growth and survival. Since nAChRs are cation channels, it can stimulate signaling cascades by the influx of Ca2+ through the opened $\alpha 7$-nAChR [49]. Ca2+ channel blockers are shown to significantly reduce DNA synthesis in response to nicotine or NNK in SCLCs [49]. Also, nAChR-mediated systemic increase in stress neurotransmitters, adrenaline, and noradrenaline, which are $\beta$-adrenergic agonists, are also shown to stimulate $\beta$-adrenergic receptor-initiated cAMP signaling and transactivation of EGFR cascade through EGF secretion in NNK-treated small airway epithelial cells $[50,51]$. Nicotine is found to induce systemic or cellular increase in noradrenaline and significantly enhance the growth and angiogenesis of pancreatic, gastric, and colon cancer-xenografts with increased expression of ERK1-ERK2, COX2, prostaglandin E2, VEGF, and transactivation of $\beta$-adrenergic as well as EGFR signaling in colon cancer cells [52-55]. Activation of ERK1-ERK2 and STAT3 in response to nicotine has also been reported in bladder cancer cells downstream of $\mathrm{nAChRs}$ and $\beta$-adrenergic receptors [56]. Importantly, apart from nAChRs, direct interaction of NNK with $\beta$-adrenergic receptor has been proposed as a novel mechanism, which may significantly enhance the high cancer-causing potential of these nitrosamines $[50,57]$. Similar to the activation via neurotransmitters, NNK binding to $\beta$-adrenergic receptor was also found to activate adenylyl cyclase-cAMP-PKA-CREB cascade and transactivation of EFGR [58]. Additionally, an additive effect of estrogen receptors and nAChRs was also demonstrated in promoting the growth of A549 tumors in athymic nude mice. Cotreatment of nicotine and estradiol resulted in increased cell proliferation as well as VEGF secretion from cancer cells, leading to increased tumor growth as well as microvascular density within the tumor [59]. Recently, the chronic exposure to estrogen and NNK was shown to have synergistic effects on cell proliferation and production of noradrenaline and adrenaline, by upregulating $\alpha 7$-nAChRs in immortalized small airway epithelial cells [60]. 


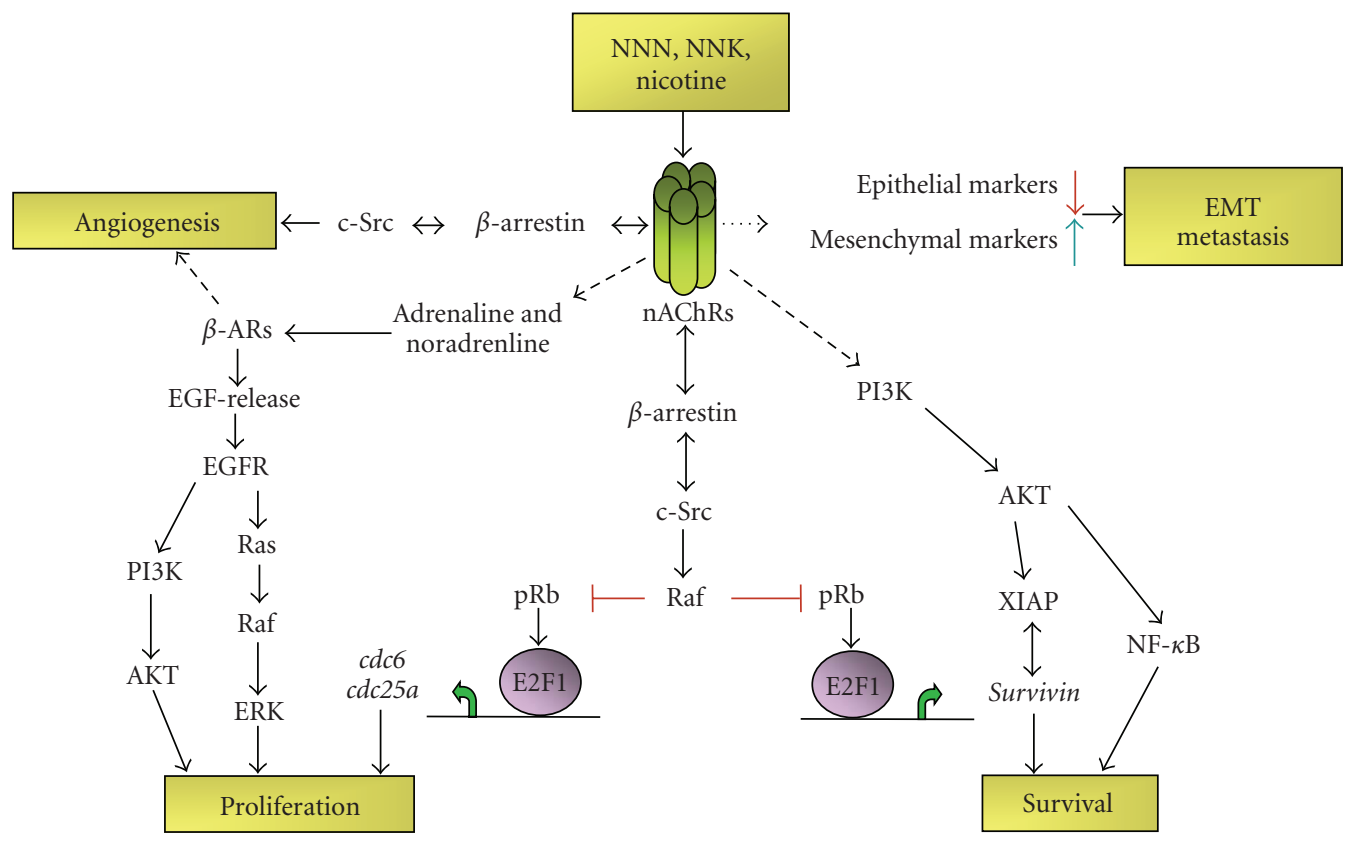

FIGURE 1: A schematic of nAChR-mediated regulation of diverse tumorigenic processes. nAChRs are activated by tobacco smoke components like NNN, NNK, and nicotine with different affinity. Induced nAChRs activate several downstream signaling pathways involved in cell proliferation, inhibition of apoptosis, metastasis, and angiogenesis in a variety of cancer and primary cells. Agonist binding to nAChR forms complex with $\beta$-arrestin and Src and results in Raf- 1 activation. Activated Raf-1 phosphorylates and inactivates Rb tumor-suppressorfunction. These in turn results in E2F-1-mediated transcriptional upregulation of target genes involved in cell proliferation, angiogenesis, and inhibition of apoptosis. Downstream effect of $\mathrm{nAChR}$ activation is also indirectly supported by the activation of $\beta$-adrenergic receptor $(\beta$-AR) signaling. Nicotine exposure directly results in metastatic dissemination of primary tumor by inducing epithelial to mesenchymal transition (EMT) in cancer cells.

\section{4. nAChRs Signaling in Cell Survival and Resistance to Apoptosis}

In addition to the effect on tumor growth, epidemiological and clinical data implicate that in patients with cancer, continued smoking causes resistance to therapy by blocking the induction of apoptosis. Various studies have linked the activation of nAChR resulting in inhibition of apoptotic pathways. In SCLC cells, NNK was shown to phosphorylate Bcl-2 at Ser70 which promoted its interaction with c-Myc that significantly enhanced the half-life of the c-Myc protein [61]. This functional cooperation of Bcl2 and c-Myc resulted in promoting cell survival and proliferation. This effect could be blocked by the PKC inhibitor staurosporin, the ERK1-ERK2 inhibitor PD98059 or silencing of MYC [61, 62]. Additionally, mesothelioma cells also showed nicotinestimulated proliferation through $\alpha 7$-nAChR-mediated $\mathrm{Ca}^{2+}$ dependent activation of the ERK1-ERK2 cascade and inhibited apoptosis by induction of NF- $\kappa \mathrm{B}$ and phosphorylation of BAD at Ser112 (Bcl-2 antagonist of cell death) [32]. In NSCLCs, constitutive activation of AKT is associated with lung cancer cell survival and resistance to chemotherapy and radiation [63]. Similarly, nicotine or NNK exposure displayed AKT-mediated growth and NF- $\kappa$ B-mediated resistance to apoptosis in human airway epithelial cells as well as lung cancer cells $[38,39]$. Further, activated AKT could directly phosphorylate Bax in vitro in nicotine treated cells.
Treatment of cells with the phosphatidylinositol 3-kinase (PI3K) inhibitor LY294002 or specific depletion of AKT was shown to block both nicotine-induced Bax phosphorylation and cisplatin resistance in NSCLC cells [64].

In addition to these signaling events, results from our laboratory revealed a significant role for the IAP proteins XIAP and survivin in nicotine-mediated chemoresistance in NSCLCs in vitro. Chromatin immunoprecipitation assays demonstrated that nicotine stimulation caused an increased recruitment of E2F1 and concomitant dissociation of retinoblastoma tumor suppressor protein $(\mathrm{Rb})$ from survivin promoter in NSCLC cells [65]. Moreover, ablation of E2F1 levels caused abrogation of survivin expression and protective effects of nicotine against cisplatin-induced apoptosis in A549 cells. In the above study, chemoprotective effect of nicotine was found to be mediated through $\alpha 3 / \beta 4$ nAChR activation and could be abrogated by agonists of these subunits. It was also found that nicotine stimulation enhanced the levels of XIAP at the protein level. Nicotine induces the activation of Akt, which is known to phosphorylate XIAP and prevent its proteasome-mediated degradation [66]. In agreement with this, an Akt inhibitor could abrogate the antiapoptotic effects of nicotine in A549 cells [65].

In other studies, the cooperative effect of nicotine and NNK was investigated for their transforming ability in various lung epithelial or cancer cells. Exposure to nicotine or the combination of nicotine and NNK for one week augmented 
Bcl-2 expression, accompanied by an increased resistance to cisplatin-induced apoptosis [67]. This study also showed that the combination treatment promoted cell proliferation and anchorage-independent growth as compared to NNK exposure alone [67]. In another study, nicotine was demonstrated to mediate prosurvival activity by Mcl-1 phosphorylation. Nicotine-induced Mcl-1 phosphorylation significantly enhanced the half-life of Mcl-1, which conferred long-term survival potential [68]. Specific depletion of Mcl-1 by RNA interference blocked nicotine-stimulated survival and enhanced apoptotic cell death [67]. Nicotine-mediated activation of $\alpha 7$-nAChR has also been linked with the expression of $\mathrm{PPAR} \beta / \delta$ protein by inhibiting AP- $2 \alpha$ protein expression and DNA binding activity to the PPAR $\beta / \delta$ gene promoter [69]. Sp1 was found to modulate this process. $\alpha 7-$ nAChR antagonist and short interfering RNA against $\alpha 7$ $\mathrm{nAChR}$ as well as inhibitors of phosphatidylinositol 3-kinase (PI3K; wortmannin and LY294002) and mammalian target of rapamycin (mTOR; rapamycin) blocked the expression of PPAR $\beta / \delta$ protein demonstrating a novel mechanism by which nicotine could promote human lung carcinoma cell growth [69]. These studies show that signaling through the nAChRs could promote cell proliferation and survival, utilizing multiple signaling cascades.

\section{5. nAChRs and Tumor Angiogenesis}

Angiogenesis, the formation of new blood vessels from pre-existing vasculature, is a complex multistep process involved in a number of physiological processes such as wound healing, embryogenesis and reproduction. In addition, angiogenesis is necessary for the sustained growth of the primary tumor as well as metastatic dissemination. Nicotine has been shown to enhance angiogenesis in many experimental systems and animal models. The proangiogenic activity of nicotine is mediated by nicotinic acetylcholine receptors, particularly $\alpha 7$ subunit. The pioneering study by Villablanca (1998) demonstrated the ability of nicotine to induce endothelial cell proliferation [24]. This observation was followed by the elegant studies from the John Cooke's laboratory suggesting a cholinergic pathway for nicotineinduced angiogenesis where they demonstrated complete inhibition of endothelial network formation using nonselective $\mathrm{nAChR}$ antagonist mecamylamine in an in vitro angiogenesis model [25]. Although several nAChR isoforms are expressed on endothelial cells, a similar inhibition was obtained only with the selective $\alpha 7$-nAChR antagonist $\alpha$ bungarotoxin, confirming the specific involvement of $\alpha 7$ nAChR. Further, in vivo pharmacological inhibition of $\mathrm{nAChR}$ and a genetic disruption of $\alpha 7-\mathrm{nAChR}$ expression significantly inhibited inflammatory angiogenesis and reduced ischemia-induced angiogenesis and tumor growth. They also provided anatomic and functional evidence for nicotine-induced angiogenesis and arteriogenesis when they observed that nicotine accelerated the growth of tumor and atheroma in association with increased neovascularization [23].

Nicotine increased endothelial-cell growth and tube formation in vitro, and accelerated fibrovascular growth in vivo. In a mouse model of hind-limb ischemia, nicotine increased capillary and collateral growth, and enhanced tissue perfusion. These effects of nicotine were mediated through nicotinic acetylcholine receptors at nicotine concentrations that are pathophysiologically relevant and suggested a possible role for the endothelial production of nitric oxide, prostacyclin, and vascular endothelial growth factor [7074]. Nicotine has been demonstrated to stimulate postnatal angiogenesis, having an antiapoptotic effect on endothelial cells. It was observed that nicotine stimulated postnatal vasculogenesis on endothelial progenitor cells (EPCs) [75]. The effect of nicotine on EPC survival was significantly enhanced under serum starvation. Furthermore, the antiapoptotic effect of nicotine was blocked completely by nicotinic acetylcholine receptor (nAChR) antagonist hexamethonium bromide [75].

Recent studies have shown that apart from cigarette smoking, exposure to secondhand smoke also could induce angiogenesis. A positive correlation between secondhand smoke exposure and concentrations of nicotine in the body was established after analyzing twenty-two studies measuring the biological effects of nicotine [76]. Further, it was found that the levels of nicotine exposure from secondhand smoke were comparable to those of active smokers. In a mouse model where Lewis lung cancer cells were implanted subcutaneously into mice, which were then exposed to sidestream smoke (SHS) or clean room air and administered vehicle or mecamylamine (an inhibitor of nAChR); SHS significantly increased tumor size, weight, capillary density, VEGF, and MCP-1 levels, and circulating endothelial progenitor cells (EPC). Mecamylamine partially inhibited the effects of SHS on these angiogenic processes and nearly abolished the effects of SHS on tumor capillary density suggesting that nicotine mediated the effects of SHS on tumor angiogenesis and growth [77].

Several recent studies have implicated that nicotineinduced angiogenesis could be mediated by growth stabilization and transmigration of endothelial progenitor cells (EPC) $[75,78,79]$. Nicotine accelerated the growth of syngenic colon cancer CMT93 cells when grown subcutaneously in mice by inducing angiogenesis via bone marrow derived EPCs [78]. To determine if the angiogenic effects of nicotine is mediated by EPC mobilization, Heeschen et al. used a model of mouse parabiosis and found that nicotine enhances EPC mobilization into the vasculature of the ischemic tissue. This effect may be due to the direct actions of nicotine on EPC proliferation, migration and/or mobilization as suggested by in vitro models [80] and plasma markers used in the investigation [79]. They also noticed that in the absence of acute ischemia, nicotine did not stimulate EPC mobilization. The activation of nAChRs in response to ischemia induced the release of proangiogenic factors like VEGF and stem cell derived factor-1, both of which are regulated by hypoxia, which in turn facilitates EPC mobilization [81]. Evidence from another study also demonstrated that nicotine promotes angiogenesis via stimulation of nAChRdependent endothelial cell migration. nAChR antagonism not only abolished nicotine-induced human microvascular endothelial cells (HMVEC) migration but also abolished 
migration induced by bFGF and attenuated migration induced by VEGF. Transcriptional profiling identified gene expression programs which were concordantly regulated by all 3 angiogens (nicotine, VEGF, and bFGF), a notable feature of which includes corepression of thioredoxin-interacting protein (TXNIP), endogenous inhibitor of the redox regulator thioredoxin. Furthermore, TXNIP repression by all 3 angiogens induced thioredoxin activity. Interestingly, nAChR antagonism abrogates growth factor (VEGF- and bFGF-) mediated induction of thioredoxin activity suggesting the requirement of $\mathrm{nAChR}$ activation in endothelial cell migration, a key angiogenesis event [82].

The proangiogenic effects of nicotine have been found to be mediated by $\alpha 7-\mathrm{nAChR}$ on endothelial cells by activating ERK/MAP kinase pathway, PI3 kinase/Akt pathway, and NF- $\kappa \mathrm{B}[23,25,83,84]$. Further, nicotine has been shown to induce the proangiogenic factors like VEGF and HIF- $1 \alpha$ in NSCLC cell lines [85]. Pharmacologically blocking $\mathrm{nAChR}$-mediated signaling cascades, including the $\mathrm{Ca} 2+/$ calmodulin, Src, protein kinase C, PI3K/Akt, MAPK/ ERK1/2, mTOR pathways, significantly attenuated nicotineinduced upregulation of HIF- $1 \alpha$. These proangiogenic and invasive effects of nicotine were partially abrogated by depleting HIF- $1 \alpha$ using siRNA techniques. Additionally, nicotine could promote angiogenesis of gastric cancers by upregulating COX2 and VEGFR2 [86]. Nicotine also enhanced the activity of matrix metalloproteinase 2 and 9 and expression of plasminogen activators in a COX2 and VEGFR2-dependent manner. The proangiogenic effect of nicotine has been shown to be dependent on Src activity by our laboratory [41]. The inhibition of Src, using chemical inhibitors or siRNA has been shown to inhibit endothelial cell proliferation, migration, and angiogenic tubule formation on matrigel. As mentioned earlier, studies from our laboratory suggest that the scaffolding protein $\beta$-arrestin-1 causes the activation of Src. Oligomeric complex comprising of $\mathrm{nAChR}, \beta$-arrestin- 1 , and Src is vital for $\mathrm{nAChR}$ signaling. In addition, depletion of $\beta$-arrestin- 1 caused abrogation of endothelial cell proliferation and angiogenic tubule formation $[29,41]$. These data suggest that nicotine behaves in a manner analogous to growth factors and induces cell cycle progression in endothelial cells.

\section{6. nAChRs in EMT and Tumor Metastasis}

Epithelial to mesenchymal transition (EMT) is a biological process that allows a polarized epithelial cell, which normally interacts with the basement membrane through its basal surface, to undergo multiple biochemical changes with a signature of more advanced and less differentiated cancer that allow it to assume a mesenchymal phenotype. This enhanced migratory capacity, invasiveness, resistance to apoptosis, and greatly increased production of ECM components [87-89]. This process results in degradation of basement membrane and the formation of a mesenchymal like cell, which can migrate away from the epithelial layer in which it originated [88]. Epithelial to mesenchymal transition (EMT) is involved in tumor progression from noninvasive tumor cells into metastatic carcinomas. Recent studies from our laboratory demonstrated that nicotine can induce invasion and migration in cell lines derived from lung cancer, breast cancer, and pancreatic cancer via $\alpha 7-\mathrm{nAChR}-$ mediated signal transduction pathways [90]. The proinvasive effects of nicotine were mediated by $\alpha 7$-nAChR in lung cancer cells while $\alpha 7$-nAChR and $\mathrm{Dh} \beta \mathrm{E}$ sensitive nAChRs mediated invasion of breast cancer cells. Nicotine was also found to inhibit anoikis in lung airway epithelial cells. Further, nicotine could induce changes in gene expression consistent with EMT. Long-term treatment of lung cancer and breast cancer cells with nicotine was found to diminish levels of epithelial markers namely $\beta$-catenin and E-cadherin and upregulate mesenchymal proteins like fibronectin and vimentin, indicative of disruption of cell-cell contacts and increased motility [90].

In addition to facilitating EMT, nicotine and NNK have been shown to affect various aspects of tumor cell invasion and migration. For example, both nicotine and NNK are shown to promote the invasion of NSCLC by phosphorylation of $\mu$ and $\mathrm{m}$-calpains [62]. Several lines of evidence show that calpain-mediated proteolysis mediates various aspects of cell physiology including cell migration and invasion. Nicotine was found to induce phosphorylation of both $\mu$ and m-calpains via $\alpha 7$-nAChR; the binding of nicotine to $\alpha 7$-nAChR in turn was found to activate Src and PKC-iota, leading to enhanced invasion and migration of NSCLC cell line H1299. Similarly, NNK also could promote invasion and migration through phosphorylation of $\mu$ and $\mathrm{m}$-calpains in a $\alpha 7$-nAChR-dependent fashion [62].

Several observations in patients suggest that those exposed to tobacco carcinogens are more likely to develop larger, more vascularized tumors with a high propensity for metastatic spread and resistance to chemotherapy [90]. About $30 \%$ of lung cancer patients who are smokers continue to smoke after they have been diagnosed [91], which might result in increased adverse medical consequences such as increased tumor progression, development of a second cancer, greater recurrence, greater cancer-related mortality and reduced quality of life $[92,93]$. While these studies demonstrate a role for tobacco carcinogens in the initiation, growth, and progression of cancers, the relative contribution of nicotine by itself to these processes is not well explored. A recent study from our laboratory demonstrated that nicotine by itself can induce the growth and metastasis of tumors in immunocompetent mice, independent of other tobacco carcinogens [26]. Nicotine administered either intraperitonially or by commercially available transdermal patches could substantially promote tumor growth. Similar effects were observed on implanted tumors as well as tumors induced by tobacco carcinogen, NNK. Furthermore, mice exposed to nicotine showed significantly enhanced lung metastasis as well as tumor recurrence after surgical removal of the primary tumor, indicating that nicotine can enhance the growth and metastasis of pre-established lung tumors [26]. As mentioned earlier, repetitive exposure to nicotine on SCLC-N417 cells resulted in neuronal-like appearance along with increased adhesion to the extracellular matrix. These changes were accompanied by enhanced migration through 
collagen matrices and adhesion to and transmigration across lymphatic endothelial cell monolayers [37].

Accumulating evidence from epidemiological studies suggest a strong association between smoking and pulmonary metastatic disease in women with breast cancer [94]. In a murine model of metastatic mammary cell cancer, cigarette smoke exposure was associated with an increase in the total pulmonary metastatic burden providing experimental support for an adverse effect of smoking on the metastatic process and suggesting a possible mechanism for smokers' increased breast cancer mortality [95]. In addition, it was observed that cigarette smoking was correlated with increased lymph node metastases at mastectomy in women older than 50 years of age suggesting that tobacco usage may potentiate the early spread of malignant disease [96]. Although numerous studies have indicated the role of nicotine exposure in tumor promotion, little is known about the molecular mechanisms by which nicotine promoted breast tumor development, especially on the metastatic process of breast cancer. At least four different subunits of nAChRs including $\alpha 5, \alpha 7, \alpha 9$, and $\beta 4$ are shown to be expressed in breast cancer cells [46]. It has been demonstrated that in addition to proliferative effect, nicotine promoted migration of breast cell lines (mammary epithelial cell line MCF10A and breast cancer cell line MCF7) through a signaling cascade involving PKC activation and its downstream effector cdc42 [46]. Exposure to nicotine has shown to increase the expression of $\alpha 9-\mathrm{nAChR}$ in breast cancer cells [47, 97]. Studies using a soft agar transforming assay and a mouse xenograft model demonstrated that noncancerous human breast epithelial cell line, MCF10A, could be neoplastically transformed by exposure to either a cigarette smoke condensate or the tobacco specific carcinogen, NNK $[98,99]$. In a recent study, $\alpha 9-\mathrm{nAChR}$ expression was silenced in MDA-MB-231 breast cancer cells which resulted in reduced proliferation and tumorigenic potential in both in vitro and in vivo assays, indicating the role of $\alpha 9-\mathrm{nAChR}$ in breast carcinogenesis [100].

Cigarette smoking has recently been recognized as a risk factor for gastric cancer [101] and long-term exposure of nicotine-induced EMT like changes in gastric cancer cell lines by activating Erk/5-Lox signaling pathway [102]. A study on the association between cigarette smoking and pancreatic cancer showed that smokers had a significantly higher risk $(70 \%)$ of developing pancreatic cancer compared to nonsmokers [103-105]. Accumulating evidence suggests that nicotine induces expression of osteopontin, a secreted phosphoprotein that confers on cancer cells a migratory phenotype and activates signaling pathways that induce cell survival, proliferation, invasion, and metastasis. Rats exposed to cigarette smoke showed a dose-dependent increase in pancreatic osteopontin expression. In addition, analysis of cancer tissues from invasive pancreatic ductal adenocarcinoma (PDA) patients, the majority of whom were smokers, showed the presence of significant amounts of osteopontin in malignant ducts and the surrounding pancreatic acini [106]. Further studies suggested that nicotine contributes to PDA metastasis by inducing MMP9 and VEGF expression and osteopontin mediated these effects [107]. An osteopontin isoform, OPNc, is selectively inducible by nicotine and is highly expressed in PDA tissues from smokers which induced the expression of monocyle chemoattractant protein (MCP-1) indicating a proinflammatory role of nicotine [108]. Altogether, these results suggest that nicotine plays a key role in the regulation of the complex cellular cascades that modulate cell adhesion, invasion, and migration leading to metastasis.

\section{Discussion and Conclusions}

Tobacco smoking is a well-documented risk factor for many cancers. As summarized in Figure 1, nicotine, the principal addictive component of tobacco smoke, as well as other nitrosamines have been found to act through nAChRs on nonneuronal cells to facilitate tumor growth, angiogenesis, metastasis, survival, and chemoresistance by regulating diverse signaling pathways. Binding of agonist to nAChR facilitates the complex formation between the receptor, scaffolding protein $\beta$-arrestin and tyrosine kinase Src. Activation of Src was found to be important for cancer as well as endothelial cell proliferation and angiogenic tube formation in vitro. Proliferative effect of nAChR-activation was also supported by indirect stimulation of $\beta$-adrenergic receptor $(\beta$-AR) signaling. Further, chemotherapy-induced apoptosis was found to be blocked by nicotine-induced survivin expression as well as NF- $\kappa \mathrm{B}$ activation. Activation of nAChR is also correlated with EMT-like changes and metastatic dissemination of primary tumor cells. Given the ability of nicotine to affect various aspects of tumor growth and metastasis, antagonists of $\mathrm{nAChR}$ signaling might be beneficial in controlling the growth and progression of tumors. Recently, alpha cobratoxin $(\alpha$-CbT) has been shown to block the growth of a variety of NSCLC and mesothelioma cell lines both in vitro and in vivo $[109,110]$. The most striking effect of $\alpha$-CbT was its ability to effectively inhibit the metastatic potential of lung cancer cells transplanted into nude mice, indicating the possibility of using nAChR antagonists as adjuvant therapy in preventing metastatic spread. At the same time, the potential side effects of nAChR antagonists on the brain and central nervous system need to be investigated before using them as a viable drug for combating lung cancer. Moreover, the direct role of nicotine alone on several aspects of tumorigenesis raises the need to revisit the potential tumor promoting effects of nicotine-replacement therapy. Also, the modulation effects of secondhand smoke on $\mathrm{nAChRs}$ require detailed investigation in the future.

\section{Acknowledgments}

Studies in the Chellappan laboratory are supported by the Grants CA127725 and CA139612.

\section{References}

[1] D. M. Burns, “Tobacco-related diseases," Seminars in Oncology Nursing, vol. 19, no. 4, pp. 244-249, 2003. 
[2] P. Vineis, M. Alavanja, P. Buffler et al., "Tobacco and cancer: recent epidemiological evidence," Journal of the National Cancer Institute, vol. 96, no. 2, pp. 99-106, 2004.

[3] "Smoking-attributable mortality, years of potential life lost, and productivity losses-United States, 2000-2004," Morbidity and Mortality Weekly Report, vol. 57, no. 45, pp. 12261228, 2008.

[4] Tobacco Smoking, vol. 38 of IARC Monogr Eval Carcinog Risk Chem Hum, IARC, Lyon, France, 1986.

[5] K. D. Brunnemann and D. Hoffmann, "Analytical studies on tobacco-specific N-nitrosamines in tobacco and tobacco smoke," Critical Reviews in Toxicology, vol. 21, no. 4, pp. 235240, 1991.

[6] S. S. Hecht, "Tobacco smoke carcinogens and lung cancer," Journal of the National Cancer Institute, vol. 91, no. 14, pp. 1194-1210, 1999.

[7] S. S. Hecht, "Cigarette smoking and lung cancer: chemical mechanisms and approaches to prevention," The Lancet Oncology, vol. 3, no. 8, pp. 461-469, 2002.

[8] S. S. Hecht, A. Abbaspour, and D. Hoffman, "A study of tobacco carcinogenesis XLII. Bioassay in A/J mice of some structural analogues of tobacco-specific nitrosamines," Cancer Letters, vol. 42, no. 1-2, pp. 141-145, 1988.

[9] Y. Sekido, K. M. Fong, and J. D. Minna, "Molecular genetics of lung cancer," Annual Review of Medicine, vol. 54, pp. 7387, 2003.

[10] J. Lindstrom, "Neuronal nicotinic acetylcholine receptors," Ion Channels, vol. 4, pp. 377-450, 1996.

[11] J. Lindstrom, "Nicotinic acetylcholine receptors in health and disease," Molecular Neurobiology, vol. 15, no. 2, pp. 193-222, 1997.

[12] N. L. Benowitz, "Neurobiology of nicotine addiction: implications for smoking cessation treatment," American Journal of Medicine, vol. 121, no. 4, supplement 1, pp. S3-S10, 2008.

[13] R. Maneckjee and J. D. Minna, "Opioid and nicotine receptors affect growth regulation of human lung cancer cell lines," Proceedings of the National Academy of Sciences of the United States of America, vol. 87, no. 9, pp. 3294-3298, 1990.

[14] H. M. Schuller, "Cell type specific, receptor-mediated modulation of growth kinetics in human lung cancer cell lines by nicotine and tobacco-related nitrosamines," Biochemical Pharmacology, vol. 38, no. 20, pp. 3439-3442, 1989.

[15] H. M. Schuller, H. K. Plummer, and B. A. Jull, "Receptormediated effects of nicotine and its nitrosated derivative NNK on pulmonary neuroendocrine cells," Anatomical Record Part A, vol. 270, no. 1, pp. 51-58, 2003.

[16] J. L. Galzi, F. Revah, A. Bessis, and J. P. Changeux, "Functional architecture of the nicotinic acetylcholine receptor: from electric organ to brain," Annual Review of Pharmacology and Toxicology, vol. 31, pp. 37-72, 1991.

[17] A. Sobel, M. Weber, and J. P. Changeux, "Large-scale purification of the acetylcholine-receptor protein in its membranebound and detergent-extracted forms from Torpedo marmorata electric organ," European Journal of Biochemistry, vol. 80, no. 1, pp. 215-224, 1977.

[18] G. S. Portugal and T. J. Gould, "Genetic variability in nicotinic acetylcholine receptors and nicotine addiction: converging evidence from human and animal research," Behavioural Brain Research, vol. 193, no. 1, pp. 1-16, 2008.

[19] I. Wessler and C. J. Kirkpatrick, "Acetylcholine beyond neurons: the non-neuronal cholinergic system in humans," British Journal of Pharmacology, vol. 154, no. 8, pp. 15581571, 2008.
[20] C. Gotti, D. Fornasari, and F. Clementi, "Human neuronal nicotinic receptors," Progress in Neurobiology, vol. 53, no. 2, pp. 199-237, 1997.

[21] H. M. Schuller and M. Orloff, "Tobacco-specific carcinogenic nitrosamines: ligands for nicotinic acetylcholine receptors in human lung cancer cells," Biochemical Pharmacology, vol. 55, no. 9, pp. 1377-1384, 1998.

[22] J. Arredondo, A. I. Chernyavsky, and S. A. Grando, "Nicotinic receptors mediate tumorigenic action of tobacco-derived nitrosamines on immortalized oral epithelial cells," Cancer Biology and Therapy, vol. 5, no. 5, pp. 511-517, 2006.

[23] C. Heeschen, J. J. Jang, M. Weis et al., "Nicotine stimulates angiogenesis and promotes tumor growth and atherosclerosis," Nature Medicine, vol. 7, no. 7, pp. 833-839, 2001.

[24] A. C. Villablanca, "Nicotine stimulates DNA synthesis and proliferation in vascular endothelial cells in vitro," Journal of Applied Physiology, vol. 84, no. 6, pp. 2089-2098, 1998.

[25] C. Heeschen, M. Weis, A. Aicher, S. Dimmeler, and J. P. Cooke, "A novel angiogenic pathway mediated by nonneuronal nicotinic acetylcholine receptors," Journal of Clinical Investigation, vol. 110, no. 4, pp. 527-536, 2002.

[26] R. Davis, W. Rizwani, S. Banerjee et al., "Nicotine promotes tumor growth and metastasis in mouse models of lung cancer," PLoS One, vol. 4, no. 10, Article ID e7524, 2009.

[27] H. K. Plummer, M. Dhar, and H. M. Schuller, "Expression of the $\alpha 7$ nicotinic acetylcholine receptor in human lung cells," Respiratory Research, vol. 6, p. 29, 2005.

[28] H. Sartelet, K. Maouche, J. L. Totobenazara et al., "Expression of nicotinic receptors in normal and tumoral pulmonary neuroendocrine cells (PNEC)," Pathology Research and Practice, vol. 204, no. 12, pp. 891-898, 2008.

[29] P. Dasgupta and S. P. Chellappan, "Nicotine-mediated cell proliferation and angiogenesis: new twists to an old story," Cell Cycle, vol. 5, no. 20, pp. 2324-2328, 2006.

[30] D. C. L. Lam, L. Girard, R. Ramirez et al., "Expression of nicotinic acetylcholine receptor subunit genes in non-smallcell lung cancer reveals differences between smokers and nonsmokers," Cancer Research, vol. 67, no. 10, pp. 46384647, 2007.

[31] S. Trombino, A. Bisio, A. Catassi, A. Cesario, C. Falugi, and P. Russo, "Role of the non-neuronal human cholinergic system in lung cancer and mesothelioma: possibility of new therapeutic strategies," Current Medicinal Chemistry-AntiCancer Agents, vol. 4, no. 6, pp. 535-542, 2004.

[32] S. Trombino, A. Cesario, S. Margaritora et al., " $\alpha 7$-nicotinic acetylcholine receptors affect growth regulation of human mesothelioma cells: role of mitogen-activated protein kinase pathway," Cancer Research, vol. 64, no. 1, pp. 135-145, 2004.

[33] A. Grozio, A. Catassi, Z. Cavalieri, L. Paleari, A. Cesario, and P. Russo, "Nicotine, lung and cancer," Anti-Cancer Agents in Medicinal Chemistry, vol. 7, no. 4, pp. 461-466, 2007.

[34] B. Jull, H. K. Plummer III, and H. Schuller, "Nicotinic receptor-mediated activation by the tobacco-specific nitrosamine NNK of a Raf-1/MAP kinase pathway, resulting in phosphorylation of c-myc in human small cell lung carcinoma cells and pulmonary neuroendocrine cells," Journal of Cancer Research and Clinical Oncology, vol. 127, no. 12, pp. 707-717, 2001.

[35] M. G. Cattaneo, A. Codignola, L. M. Vicentini, F. Clementi, and E. Sher, "Nicotine stimulates a serotonergic autocrine loop in human small-cell lung carcinoma," Cancer Research, vol. 53, no. 22, pp. 5566-5568, 1993. 
[36] A. Codignola, "Serotonin release and cell proliferation are under the control of $\alpha$-bungarotoxin-sensitive nicotinic receptors in small-cell lung carcinoma cell lines," FEBS Letters, vol. 342, no. 3, pp. 286-290, 1994.

[37] E. Martínez-García, M. Irigoyen, Ó. González-Moreno et al., "Repetitive nicotine exposure leads to a more malignant and metastasis-prone phenotype of SCLC: a molecular insight into the importance of quitting smoking during treatment," Toxicological Sciences, vol. 116, no. 2, pp. 467-476, 2010.

[38] J. Tsurutani, S. S. Castillo, J. Brognard et al., "Tobacco components stimulate Akt-dependent proliferation and NFKBdependent survival in lung cancer cells," Carcinogenesis, vol. 26, no. 7, pp. 1182-1195, 2005.

[39] K. A. West, J. Brognard, A. S. Clark et al., "Rapid Akt activation by nicotine and a tobacco carcinogen modulates the phenotype of normal human airway epithelial cells," Journal of Clinical Investigation, vol. 111, no. 1, pp. 81-90, 2003.

[40] D. C. Blake, O. R. Mikse, W. M. Freeman, and C. R. Herzog, "FOXO3a elicits a pro-apoptotic transcription program and cellular response to human lung carcinogen nicotine-derived nitrosaminoketone (NNK)," Lung Cancer, vol. 67, no. 1, pp. 37-47, 2010.

[41] P. Dasgupta, S. Rastogi, S. Pillai et al., "Nicotine induces cell proliferation by $\beta$-arrestin-mediated activation of Src and Rb-Raf-1 pathways," Journal of Clinical Investigation, vol. 116, no. 8, pp. 2208-2217, 2006.

[42] J. Arredondo, A. I. Chernyavsky, D. L. Jolkovsky, K. E. Pinkerton, and S. A. Grando, "Receptor-mediated tobacco toxicity: acceleration of sequential expression of $\alpha 5$ and $\alpha 7$ nicotinic receptor subunits in oral keratinocytes exposed to cigarette smoke," FASEB Journal, vol. 22, no. 5, pp. 13561368, 2008.

[43] J. Arredondo, A. I. Chernyavsky, and S. A. Grando, "SLURP1 and -2 in normal, immortalized and malignant oral keratinocytes," Life Sciences, vol. 80, no. 24-25, pp. 22432247, 2007.

[44] A. Pettersson, G. Nylund, A. Khorram-Manesh, S. Nordgren, and D. S. Delbro, "Nicotine induced modulation of SLURP-1 expression in human colon cancer cells," Autonomic Neuroscience, vol. 148, no. 1-2, pp. 97-100, 2009.

[45] E. Gemenetzidis, A. Bose, A. M. Riaz et al., "FOXM1 upregulation is an early event in human squamous cell carcinoma and it is enhanced by nicotine during malignant transformation," PLoS One, vol. 4, no. 3, Article ID e4849, 2009.

[46] J. Guo, S. Ibaragi, T. Zhu et al., "Nicotine promotes mammary tumor migration via a signaling cascade involving protein kinase C and cdc42," Cancer Research, vol. 68, no. 20, pp. 8473-8481, 2008.

[47] C.-S. Chen, C.-H. Lee, C.-D. Hsieh et al., "Nicotine-induced human breast cancer cell proliferation attenuated by garcinol through down-regulation of the nicotinic receptor and cyclin D3 proteins," Breast Cancer Research and Treatment, vol. 125, no. 1, pp. 73-87, 2011.

[48] N. Hirata, Y. Sekino, and Y. Kanda, "Nicotine increases cancer stem cell population in MCF-7 cells," Biochemical and Biophysical Research Communications, vol. 403, no. 1, pp. 138-143, 2010.

[49] B. J. Sheppard, M. Williams, H. K. Plummer III, and H. M. Schuller, "Activation of voltage-operated $\mathrm{Ca}^{2+}$-channels in human small cell lung carcinoma by the tobaccospecific nitrosamine 4-(methylnitrosamino)-1-(3-pyridyl)1-butanone," International Journal of Oncology, vol. 16, no. 3, pp. 513-518, 2000.
[50] H. M. Schuller, P. K. Tithof, M. Williams, and H. K. Plummer III, "The tobacco-specific carcinogen 4-(methylnitrosamino)-1-(3-pyridyl)-1- butanone is a $\beta$-adrenergic agonist and stimulates DNA synthesis in lung adenocarcinoma via $\beta$-adrenergic receptor-mediated release of arachidonic acid," Cancer Research, vol. 59, no. 18, pp. 4510-4515, 1999.

[51] E. Laag, M. Majidi, M. Cekanova, T. Masi, T. Takahashi, and H. M. Schuller, "NNK activates ERK1/2 and CREB/ATF-1 via $\beta$-1-AR and EGFR signaling in human lung adenocarcinoma and small airway epithelial cells," International Journal of Cancer, vol. 119, no. 7, pp. 1547-1552, 2006.

[52] H. A. N. Al-Wadei, H. K. Plummer III, and H. M. Schuller, "Nicotine stimulates pancreatic cancer xenografts by systemic increase in stress neurotransmitters and suppression of the inhibitory neurotransmitter $\gamma$-aminobutyric acid," Carcinogenesis, vol. 30, no. 3, pp. 506-511, 2009.

[53] V. Y. Shin, W. K. K. Wu, K. M. Chu et al., "Functional role of $\beta$-adrenergic receptors in the mitogenic action of nicotine on gastric cancer cells," Toxicological Sciences, vol. 96, no. 1, pp. 21-29, 2007.

[54] V. Y. Shin, W. K. K. Wu, YI. N. Ye et al., "Nicotine promotes gastric tumor growth and neovascularization by activating extracellular signal-regulated kinase and cyclooxygenase-2," Carcinogenesis, vol. 25, no. 12, pp. 2487-2495, 2004.

[55] H. P. S. Wong, LE. Yu, E. K. Y. Lam, E. K. K. Tai, W. K. K. Wu, and C. H. Cho, "Nicotine promotes colon tumor growth and angiogenesis through $\beta$-adrenergic activation," Toxicological Sciences, vol. 97, no. 2, pp. 279-287, 2007.

[56] R. J. Chen, Y. S. Ho, H. R. Guo, and Y. J. Wang, "Rapid activation of Stat 3 and ERK1/2 by nicotine modulates cell proliferation in human bladder cancer cells," Toxicological Sciences, vol. 104, no. 2, pp. 283-293, 2008.

[57] H. M. Schuller, B. Porter, and A. Riechert, "Beta-adrenergic modulation of NNK-induced lung carcinogenesis in hamsters," Journal of Cancer Research and Clinical Oncology, vol. 126, no. 11, pp. 624-630, 2000.

[58] H. M. Schuller, "Is cancer triggered by altered signalling of nicotinic acetylcholine receptors?" Nature Reviews Cancer, vol. 9, no. 3, pp. 195-205, 2009.

[59] M. J. Jarzynka, P. Guo, I. Bar-Joseph, B. Hu, and S. Y. Cheng, "Estradiol and nicotine exposure enhances A549 bronchioloalveolar carcinoma xenograft growth in mice through the stimulation of angiogenesis," International Journal of Oncology, vol. 28, no. 2, pp. 337-344, 2006.

[60] H. A. N. Al-Wadei, M. H. Al-Wadei, T. Masi, and H. M. Schuller, "Chronic exposure to estrogen and the tobacco carcinogen NNK cooperatively modulates nicotinic receptors in small airway epithelial cells," Lung Cancer, vol. 69, no. 1, pp. 33-39, 2010.

[61] Z. Jin, F. Gao, T. Flagg, and X. Deng, "Tobaccospecific nitrosamine 4-(methylnitrosamino)-1-(3-pyridyl)1-butanone promotes functional cooperation of Bcl2 and cMyc through phosphorylation in regulating cell survival and proliferation," Journal of Biological Chemistry, vol. 279, no. 38, pp. 40209-40219, 2004.

[62] L. Xu and X. Deng, "Tobacco-specific nitrosamine 4-(methylnitrosamino)-1-(3-pyridyl)-1-butanone induces phosphorylation of $\mu$ - and $\mathrm{m}$-calpain in association with increased secretion, cell migration, and invasion," Journal of Biological Chemistry, vol. 279, no. 51, pp. 53683-53690, 2004.

[63] J. Brognard, A. S. Clark, Y. Ni, and P. A. Dennis, "Akt/pbotein kinace $\mathrm{B}$ is constitutively active in non-small cell lung cancer cells and promotes cellular survival and resistance to 
chemotherapy and radiation," Cancer Research, vol. 61, no. 10, pp. 3986-3997, 2001.

[64] M. Xin and X. Deng, "Nicotine inactivation of the proapoptotic function of Bax through phosphorylation," Journal of Biological Chemistry, vol. 280, no. 11, pp. 10781-10789, 2005.

[65] P. Dasgupta, R. Kinkade, B. Joshi, C. DeCook, E. Haura, and S. Chellappan, "Nicotine inhibits apoptosis induced by chemotherapeutic drugs by up-regulating XIAP and survivin," Proceedings of the National Academy of Sciences of the United States of America, vol. 103, no. 16, pp. 6332-6337, 2006.

[66] H. C. Dan, M. Sun, S. Kaneko et al., "Akt phosphorylation and stabilization of X-linked inhibitor of apoptosis protein (XIAP)," Journal of Biological Chemistry, vol. 279, no. 7, pp. 5405-5412, 2004.

[67] T. Nishioka, J. Guo, D. Yamamoto, L. Chen, P. Huppi, and C. Y. Chen, "Nicotine, through upregulating pro-survival signaling, cooperates with NNK to promote transformation," Journal of Cellular Biochemistry, vol. 109, no. 1, pp. 152-161, 2010.

[68] J. Zhao, M. Xin, T. Wang, Y. Zhang, and X. Deng, "Nicotine enhances the antiapoptotic function of mcl-1 through phosphorylation," Molecular Cancer Research, vol. 7, no. 12, pp. 1954-1961, 2009.

[69] X. Sun, J. D. Ritzenthaler, X. Zhong, Y. Zheng, J. Roman, and S. Han, "Nicotine stimulates PPAR $\beta / \delta$ expression in human lung carcinoma cells through activation of $\mathrm{P} 13 \mathrm{~K} / \mathrm{mTOR}$ and suppression of AP-2 $\alpha$," Cancer Research, vol. 69, no. 16, pp. 6445-6453, 2009.

[70] O. Boutherin-Falson and N. Blaes, "Nicotine increases basal prostacyclin production and DNA synthesis of human endothelial cells in primary cultures," Nouvelle Revue Francaise d'Hematologie, vol. 32, no. 4, pp. 253-258, 1990.

[71] R. M. Pittilo, H. A. Bull, S. Gulati et al., "Nicotine and cigarette smoking: effects on the ultrastructure of aortic endothelium," International Journal of Experimental Pathology, vol. 71, no. 4, pp. 573-586, 1990.

[72] C. S. Carty, P. D. Soloway, S. Kayastha et al., "Nicotine and cotinine stimulate secretion of basic fibroblast growth factor and affect expression of matrix metalloproteinases in cultured human smooth muscle cells," Journal of Vascular Surgery, vol. 24, no. 6, pp. 927-935, 1996.

[73] W. O. Lee and S. M. Wright, "Production of endothelin by cultured human endothelial cells following exposure to nicotine or caffeine," Metabolism, vol. 48, no. 7, pp. 845-848, 1999.

[74] A. Cucina, P. Sapienza, V. Corvino et al., "Nicotine-induced smooth muscle cell proliferation is mediated through bFGF and TGF- $\beta$," Surgery, vol. 127, no. 3, pp. 316-322, 2000.

[75] A. Sugimoto, H. Masuda, M. Eguchi, H. Iwaguro, T. Tanabe, and T. Asahara, "Nicotine enlivenment of blood flow recovery following endothelial progenitor cell transplantation into ischemic hindlimb," Stem Cells and Development, vol. 16, no. 4, pp. 649-656, 2007.

[76] C. T. C. Okoli, T. Kelly, and E. J. Hahn, "Secondhand smoke and nicotine exposure: a brief review," Addictive Behaviors, vol. 32, no. 10, pp. 1977-1988, 2007.

[77] B. Q. Zhu, C. Heeschen, R. E. Sievers et al., "Second hand smoke stimulates tumor angiogenesis and growth," Cancer Cell, vol. 4, no. 3, pp. 191-196, 2003.

[78] T. Natori, M. Sata, M. Washida, Y. Hirata, R. Nagai, and M. Makuuchi, "Nicotine enhances neovascularization and promotes tumor growth," Molecules and Cells, vol. 16, no. 2, pp. 143-146, 2003.
[79] C. Heeschen, E. Chang, A. Aicher, and J. P. Cooke, "Endothelial progenitor cells participate in nicotine-mediated angiogenesis," Journal of the American College of Cardiology, vol. 48, no. 12, pp. 2553-2560, 2006.

[80] X. Wang, J. Zhu, J. Chen, and Y. Shang, "Effects of nicotine on the number and activity of circulating endothelial progenitor cells," Journal of Clinical Pharmacology, vol. 44, no. 8, pp. 881-889, 2004.

[81] A. Avogaro and G. P. Fadini, "The Janus face of nicotinic angiogenesis," Journal of the American College of Cardiology, vol. 48, no. 12, pp. 2561-2563, 2006.

[82] M. K. C. Ng, J. Wu, E. Chang et al., "A central role for nicotinic cholinergic regulation of growth factor-induced endothelial cell migration," Arteriosclerosis, Thrombosis, and Vascular Biology, vol. 27, no. 1, pp. 106-112, 2007.

[83] C. Heeschen, M. Weis, and J. P. Cooke, "Nicotine promotes arteriogenesis," Journal of the American College of Cardiology, vol. 41, no. 3, pp. 489-496, 2003.

[84] J. P. Cooke and H. Bitterman, "Nicotine and angiogenesis: a new paradigm for tobacco-related diseases," Annals of Medicine, vol. 36, no. 1, pp. 33-40, 2004.

[85] Q. Zhang, X. Tang, Z. F. Zhang, R. Velikina, S. Shi, and A. D. Le, "Nicotine induces hypoxia-inducible factor$1 \alpha$ expression in human lung cancer cells via nicotinic acetylcholine receptor-mediated signaling pathways," Clinical Cancer Research, vol. 13, no. 16, pp. 4686-4694, 2007.

[86] V. Y. Shin, W. K. K. Wu, K. M. Chu et al., "Nicotine induces cyclooxygenase-2 and vascular endothelial growth factor receptor-2 in association with tumor-associated invasion and angiogenesis in gastric cancer," Molecular Cancer Research, vol. 3, no. 11, pp. 607-615, 2005.

[87] S. A. Mani, W. Guo, M. J. Liao et al., "The epithelialmesenchymal transition generates cells with properties of stem cells," Cell, vol. 133, no. 4, pp. 704-715, 2008.

[88] R. Kalluri and R. A. Weinberg, "The basics of epithelialmesenchymal transition," Journal of Clinical Investigation, vol. 119, no. 6, pp. 1420-1428, 2009.

[89] K. Polyak and R. A. Weinberg, "Transitions between epithelial and mesenchymal states: acquisition of malignant and stem cell traits," Nature Reviews Cancer, vol. 9, no. 4, pp. 265273, 2009.

[90] P. Dasgupta, W. Rizwani, S. Pillai et al., "Nicotine induces cell proliferation, invasion and epithelial-mesenchymal transition in a variety of human cancer cell lines," International Journal of Cancer, vol. 124, no. 1, pp. 36-45, 2009.

[91] A. Gautam, Z. R. Li, and G. Bepler, "RRM1-induced metastasis suppression through PTEN-regulated pathways," Oncogene, vol. 22, no. 14, pp. 2135-2142, 2003.

[92] Y. I. Garces, P. Yang, J. Parkinson et al., "The relationship between cigarette smoking and quality of life after lung cancer diagnosis," Chest, vol. 126, no. 6, pp. 1733-1741, 2004.

[93] A. Johnston-Early, M. H. Cohen, and J. D. Minna, "Smoking abstinence and small cell lung cancer survival. An association," Journal of the American Medical Association, vol. 244, no. 19, pp. 2175-2179, 1980.

[94] S. Murin and J. Inciardi, "Cigarette smoking and the risk of pulmonary metastasis from breast cancer," Chest, vol. 119, no. 6, pp. 1635-1640, 2001.

[95] S. Murin, K. E. Pinkerton, N. E. Hubbard, and K. Erickson, "The effect of cigarette smoke exposure on pulmonary metastatic disease in a murine model of metastatic breast cancer," Chest, vol. 125, no. 4, pp. 1467-1471, 2004. 
[96] H. W. Daniell, "Increased lymph node metastases at mastectomy for breast cancer associated with host obesity, cigarette smoking, age, and large tumor size," Cancer, vol. 62, no. 2, pp. 429-435, 1988.

[97] Y. L. Shih, H. C. Liu, C. S. Chen et al., "Combination treatment with luteolin and quercetin enhances antiproliferative effects in nicotine-treated MDA-MB-231 cells by down-regulating nicotinic acetylcholine receptors," Journal of Agricultural and Food Chemistry, vol. 58, no. 1, pp. 235-241, 2010.

[98] J. Mei, H. Hu, M. McEntee, H. K. Plummer III, P. Song, and H. C. R. Wang, "Transformation of non-cancerous human breast epithelial cell line MCF10A by the tobacco-specific carcinogen NNK," Breast Cancer Research and Treatment, vol. 79, no. 1, pp. 95-105, 2003.

[99] N. Siriwardhana, S. Choudhary, and H. C. R. Wang, "Precancerous model of human breast epithelial cells induced by NNK for prevention," Breast Cancer Research and Treatment, vol. 109, no. 3, pp. 427-441, 2008.

[100] C.-H. Lee, C.-S. Huang, C.-S. Chen et al., "Overexpression and activation of the $\alpha 9$-nicotinic receptor during tumorigenesis in human breast epithelial cells," Journal of the National Cancer Institute, vol. 102, no. 17, pp. 1322-1335, 2010.

[101] R. Ladeiras-Lopes, A. K. Pereira, A. Nogueira et al., "Smoking and gastric cancer: systematic review and meta-analysis of cohort studies," Cancer Causes and Control, vol. 19, no. 7, pp. 689-701, 2008.

[102] V. Y. Shin, H. C. Jin, E. K. O. Ng, J. J. Y. Sung, K. M. Chu, and C. H. Cho, "Activation of 5-lipoxygenase is required for nicotine mediated epithelial-mesenchymal transition and tumor cell growth," Cancer Letters, vol. 292, no. 2, pp. 237$245,2010$.

[103] T. M. Mack, M. C. Yu, R. Hanisch, and B. E. Henderson, "Pancreas cancer and smoking, beverage consumption, and past medical history," Journal of the National Cancer Institute, vol. 76, no. 1, pp. 49-60, 1986.

[104] D. C. Farrow and S. Davis, "Risk of pancreatic cancer in relation to medical history and the use of tobacco, alcohol and coffee," International Journal of Cancer, vol. 45, no. 5, pp. 816-820, 1990.

[105] D. T. Silverman, J. A. Dunn, R. N. Hoover et al., "Cigarette smoking and pancreas cancer: a case-control study based on direct interviews," Journal of the National Cancer Institute, vol. 86, no. 20, pp. 1510-1516, 1994.

[106] G. Chipitsyna, Q. Gong, R. Anandanadesan et al., "Induction of osteopontin expression by nicotine and cigarette smoke in the pancreas and pancreatic ductal adenocarcinoma cells," International Journal of Cancer, vol. 125, no. 2, pp. 276-285, 2009.

[107] M. Lazar, J. Sullivan, G. Chipitsyna et al., "Involvement of osteopontin in the matrix-degrading and proangiogenic changes mediated by nicotine in pancreatic cancer cells," Journal of Gastrointestinal Surgery, vol. 14, no. 10, pp. 15661577, 2010.

[108] M. Lazar, J. Sullivan, G. Chipitsyna et al., "Induction of monocyte chemoattractant protein-1 by nicotine in pancreatic ductal adenocarcinoma cells: role of osteopontin," Surgery, vol. 148, no. 2, pp. 298-309, 2010.

[109] L. Paleari, E. Negri, A. Catassi et al., "Inhibition of nonneuronal $\alpha 7$-nicotinic receptor for lung cancer treatment," American Journal of Respiratory and Critical Care Medicine, vol. 179, no. 12, pp. 1141-1150, 2009.
[110] A. Catassi, L. Paleari, D. Servent et al., "Targeting $\alpha 7-$ nicotinic receptor for the treatment of pleural mesothelioma," European Journal of Cancer, vol. 44, no. 15, pp. 22962311, 2008. 


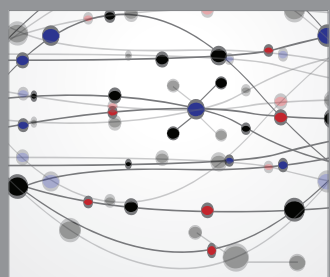

The Scientific World Journal
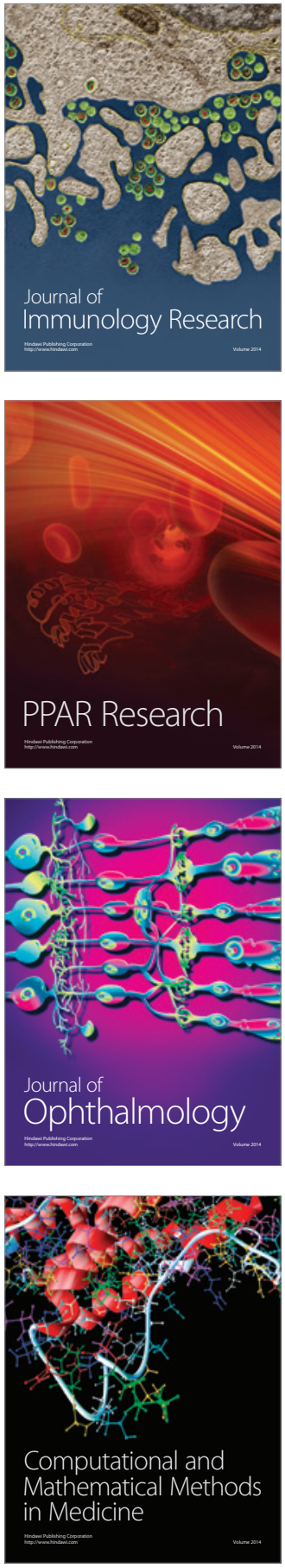

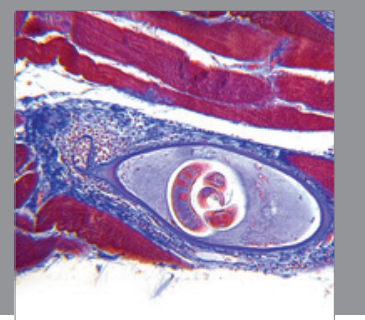

Gastroenterology

Research and Practice
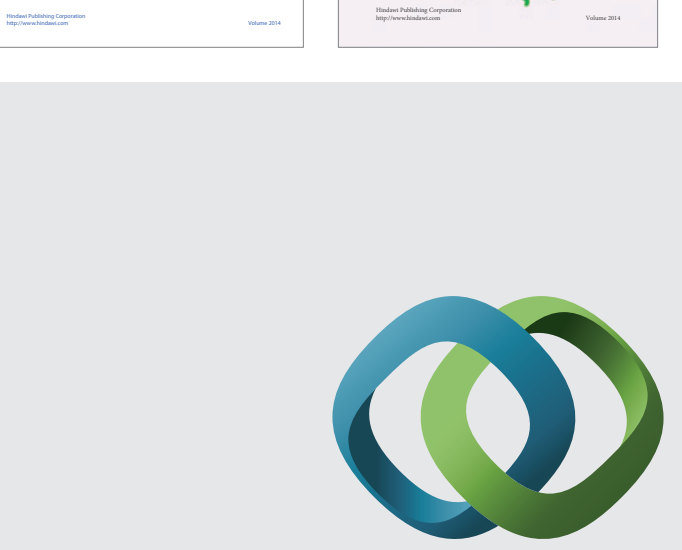

\section{Hindawi}

Submit your manuscripts at

http://www.hindawi.com
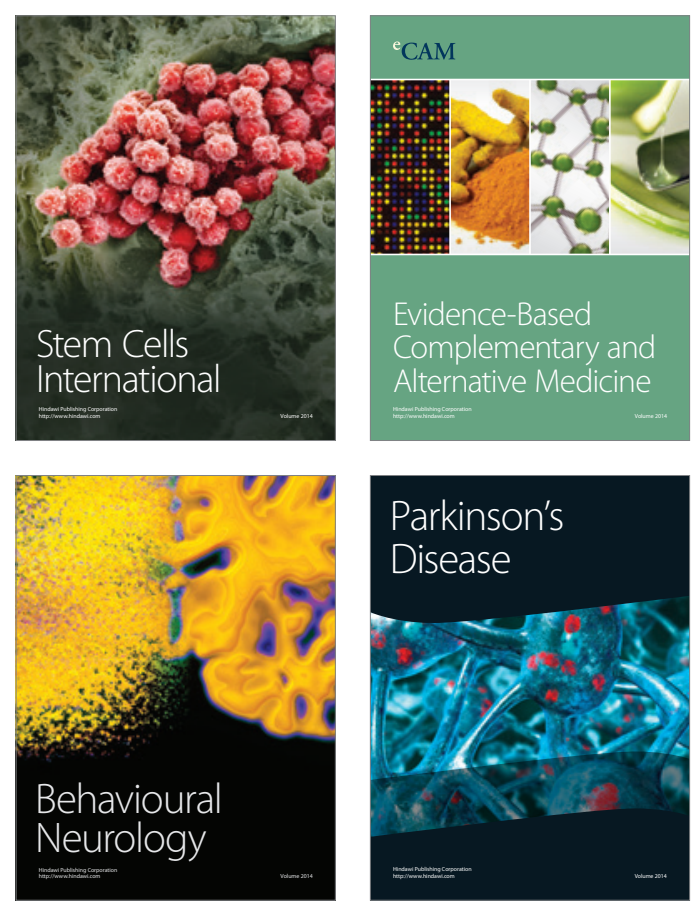

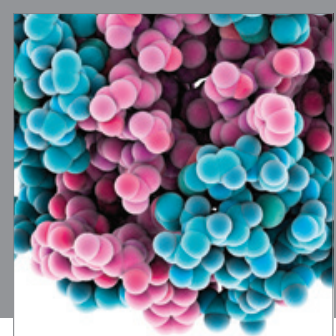

Journal of
Diabetes Research

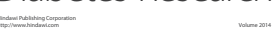

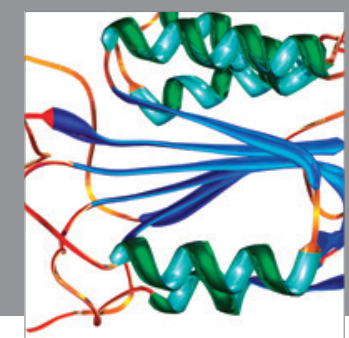

Disease Markers
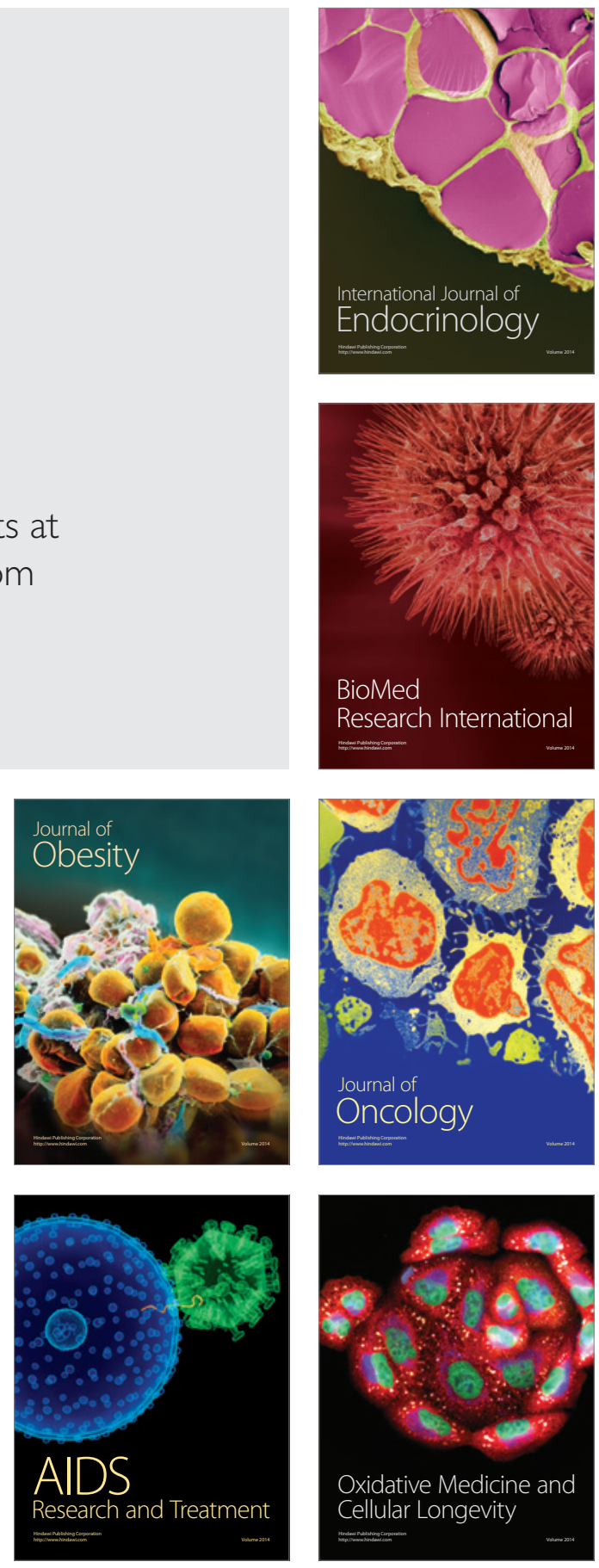